\title{
The Impact of a Professional
}

\section{Development Program Integrating} Informal Science Education on Early Childhood Teachers' Self-Efficacy and Beliefs About Inquiry-Based Science Teaching

\author{
Emilio Duran, Bowling Green State University \\ Lena Ballone-Duran, Bowling Green State University \\ Jodi Haney, Bowling Green State University \\ Svetlana Beltyukova, University of Toledo
}

\begin{abstract}
This report aimed to measure the impact of a unique professional development program entitled Project ASTER III (Active Science Teaching Encourages Reform) on teachers' self-efficacy and perceptions about inquiry-based science teaching. Project ASTER III enabled teachers to explore inquiry-based science teaching throughexhibit-based hands-on/ minds-on investigations at a science museum and to develop a science curriculum aligned with museum exhibits and state and national science education standards. Quantitative data indicated that teacher beliefs were positively and significantly impacted by the professional development program and confirmed that programs like ASTER III are effective but need to be provided on a continuous basis to reinforce these beliefs in the teachers. Finally, three themes emerged from the analysis of the qualitative data from the participant journals: (1) impact on teacher understanding of inquiry, (2) increased confidence about science teaching, and (3) benefits of collaboration.
\end{abstract}

\section{Introduction}

The influence of informal science education has long been acknowledged as an effective tool to enhance the more formal methods of classroom teaching and learning. The successful integration of informal science education can serve as a powerful catalyst encouraging students and teachers to have unique, memorable, and motivating learning experiences in settings that extend far beyond classrooms. Community resources such as zoos, science centers, parks, planetariums, and art museums can be highly engaging places for science teachers and students. The establishment in 1984 of the Informal Science Education program of the National Science Foundation (NSF) is a testament to the nation's high regard for the opportunities that these resources provide to students and teachers. Furthermore, NSF is committed to the principle that scientific discoveries can be understood and enjoyed by all, and it has long recognized that understanding and excitement about science come from self-directed, voluntary explorations. NSF calls these processes 
"informal learning." In an era in which state and national standards permeate the school curriculum, designing inquiry-based approaches at informal science centers while aligning with state and national science standards can pose a challenge to educators, curriculum directors, and informal science center directors. It is welldocumented that teacher self-efficacy is associated with inquiry-based teaching. Therefore, it is imperative that professional development programs in both formal and informal settings help the teacher feel more comfortable teaching science. This paper explores the effect of a unique professional development program aimed at improving teachers' self-efficacy and perceptions about inquiry-based science teaching while designing effective curriculum and field trips for K-3 students all aligned with state and national science education standards.

\section{Literature Review}

\section{Informal Science Education}

Worldwide support of the valuable role informal science centers play in the science curriculum has been reflected throughout multiple reform documents. In the United States, for instance, the National Science Education Standards (NSES) call upon educators to identify resources outside of the school setting as they reveal, "The classroom is a limited environment. The school science program must extend beyond the walls of the school to the resources of the community" (National Research Council [NRC], 1996, p. 45). Additional support is expressed in the National Science Teachers Association's (NSTA) (1999) Position Statement on Informal Science Education that states, "NSTA recognizes and encourages the development of sustained links between the informal institutions and schools." Furthermore, "NSTA strongly supports and advocates informal science education because we share a common mission and vision articulated by the National Science Education Standards. . . . Informal science education complements, supplements, deepens, and enhances classroom science studies. It increases the amount of time participants can be engaged in a project or topic. It can be the proving ground for curriculum materials." Recently, McComas (2006) explained that museums have become purposefully more engaging and interactive as a way to encourage inquiry and hands-on investigation. This trend is in contrast to the past when museums tended to operate on a look but do not touch philosophy.

The positive impact of integrating museum learning into the science classroom has been widely reported in the literature (Falk \& Dierking, 1997; Morrell, 2003; Price \& Hein, 1991; Rennie \& McClafferty, 1995). For example, Ramey-Gassert, Walberg, and Walberg (1994) examined the collaborative efforts between science museums and schools and provided a list of benefits of museum learning such as providing opportunities for active engagement with real objects intended to enhance the classroom learning experiences. These authors emphasized that more collaborative efforts are needed between science museums and schools as both entities complement each other through different facets of learning. Furthermore, the cognitive impact of a field trip experience was examined by Morrell (2003) and revealed that students increased and retained their knowledge after participation in the field trip experience. An earlier study by Falk and Dierking (1997) found that nearly $100 \%$ of the individuals they interviewed could remember at least one thing they learned during an early-elementary school field trip, and most individuals could relate three or more things many years after the field trip ended, thus showing the impact a field trip can have on students. 
Although many educators support using resources provided by informal science museums, many teachers may not be familiar with how to best integrate those resources into the classroom setting thus resulting in unproductive field trips (Griffin \& Symington, 1997). In fact, many teachers may view informal science centers as simply an enjoyable field trip experience that may or may not directly align with state science education standards. Ramey-Gassert et al. (1994) revealed, "Traditionally educators have viewed visits to museums from the limited perspective of a one-time trip often disconnected from the classroom curriculum" (p. 347). McComas (2006) cautioned that if the experience is not designed properly, students could actually leave a science museum field trip with new misconceptions. It is especially important to make cognitive connections to the school curriculum. Kisiel (2006) described a list of helpful strategies for creating a positive learning experience for field trips. Of particular importance is planning ways to fully integrate the field trip into the classroom that makes it part of the curriculum and not as an add-on event. And, since current science reform recommendations (NRC, 1996) clearly establish guidelines for what should be taught in the classroom and most states currently employ some type of achievement testing, it is critical that informal science museums become connected to state and national standards in order to meet the needs of the students, teacher, and parents.

\section{Theory of Planned Behavior, Teacher Self-Efficacy, and Professional Development}

In the theory of planned behavior (Ajzen, 1985), beliefs are used to predict an individual's intention to engage in a behavior. Three direct variables are needed in order to predict intention and behavior. They include the attitude toward the behavior $(\mathrm{AB})$, the subjective norm (SN), and the perceived behavioral control (PBC). The AB variable includes the individual's beliefs that reflect the extent to which the individual believes that engaging in the behavior will lead to favorable outcomes. Thus, the attitude represents a personal component. The SN variable includes the beliefs regarding the people who are supportive of engaging in the behavior. This component represents a social component and measures the extent to which the individual believes that other people, important to his or her life, think the behavior should be performed. Lastly, the PBC variable includes the salient beliefs regarding both the resources and the obstacles that either facilitate or impede engagement in the behavior. In other words, PBC reflects the individual's perceptions regarding how the behavior is complicated by internal (e.g., skill, ability, knowledge) and external (e.g., resources, opportunity, cooperation) factors. Ajzen explained that the intent, the AB, the SN, and the PBC constructs are directly linked to behavior and that the relationship is causal and unidirectional.

As schools transition through a plethora of changes in science education, it is also critical to acknowledge the important role that staff development plays in this process. The NSES (NRC, 1996) reveal that the professional development of science teachers should be accomplished by actively involving teachers in scientific investigations that would allow them to examine both the content and process of science and incorporate opportunities for reflection and collaboration. In addition, good science teacher development is characterized by "integrating knowledge of sciences, learning, pedagogy, and students" (p. 62), by "building understanding and ability for lifelong learning" (p. 68), and by experiencing a "coherent and integrated in-service program" (p. 70). This can be a lofty goal considering educational researchers have also demonstrated that many elementary teachers do not teach science and lack a conceptual understanding of the content. It has long been recognized that there are serious concerns regarding elementary science teachers' attitudes, beliefs, and self-efficacy about science teaching. 
The evaluation of teacher self-efficacy as an indicator of teacher classroom behavior has been studied by many researchers in the field of science education (Brickhouse, 1994; Czerniak \& Chiarelott, 1990; Czerniak \& Shriver, 1994; Levitt, 2001; Lumpe, Czerniak, Haney, \& Beltyukova, 2004; Lumpe, Haney, \& Czerniak, 2000; Moseley, Reinke, \& Bookout, 2003; Ramey-Gassert, Shroyer, \& Staver, 1996). Hence, Bandura's (1981) description of self-efficacy as a situation-specific construct can be applied to science teaching and may help to explain teachers' thought processes and behaviors related to science teaching. All these data taken together suggest that it is critical to examine the role of self-efficacy and the context of science teaching (Plourde, 2002) as such beliefs have the possibility of impacting the quality of teaching and student learning (Lumpe et al., 2000). In a related study, a professional development program that focused on science content and pedagogy involved K-3 teachers as they explore inquiry-based science alongside scientists and science educators (Duran \& Ballone-Duran, 2005). The study found that the professional program had a positive impact on the teachers' self-efficacy and outcome expectancy as their scores on both of these constructs significantly increased after participation in the project. The researchers argued that self-efficacy was impacted due to the inclusion of key elements in their professional development model. These elements included (1) a strong partnership between school districts and institutions of higher education, (2) a unique collaboration between science educators and scientists, (3) a three-phase training program designed around the school district's adopted course of study and the NSES, (4) the integration of community resources, (5) a partnership with preservice teachers, (6) the development of teacher leaders, and (7) a comprehensive program evaluation. The importance of sustaining high levels of efficacy long after the professional development experience is a vital component to the reform process.

\section{Background of Project ASTER}

This report describes a professional development program entitled Project ASTER III (Active Science Teaching Encourages Reform), which was a collaborative effort between Bowling Green State University, The University of Toledo, K-3 teachers, and the interactive science museum COSI (Center Of Science and Industry) Toledo. This effort aimed to develop a science curriculum aligned with COSI exhibits and state and national science education standards. This program also sought to enable teachers to explore inquiry-based science teaching through exhibit-based hands-on/minds-on investigations.

COSI Toledo has provided powerful science learning experiences to over two million visitors through discovery and exploration. The museum's location in downtown Toledo, Ohio, offers innovative exhibits and programs that educate, entertain, and inspire young people and adults in science and technology. With more than 300 exhibits and interactive demonstrations, COSI has the sources to create highly effective, inquiry-based experiences for visitors of all ages since its opening in 1997. Coupling hands-on experiences with the latest technologies and research, COSI has provided learners of all ages with opportunities to uncover the mysteries of science through inquiry-based learning environments for students and teachers. COSI's partnership with the Exploratorium, a world leader in inquiry-based science learning, exhibit development, and educational reform, was established in conjunction with NSF to aid science centers in building their capacity for improving science education in their regions. This partnership (Ex-Net) has brought a series of exhibits to COSI that are designed to foster effective inquiry-based instruction. 
The main goal of ASTER III was to build on the success of a professional development model implemented during Project ASTER I and II (Duran \& Ballone-Duran, 2005). Results from these Ohio Board of Regents funded projects demonstrated a positive impact on teachers' self-efficacy and outcome expectancy. Focusing on increasing teacher science content knowledge and on effective inquiry-based pedagogy, Project ASTER III differed in its design and activities from its precursor projects. Specifically, Project ASTER III modeled inquiry applications in informal learning environments as curriculum development teams consisting of university scientists, science educators, K-3 teachers, and COSI educators developed 5E lesson plans (Bybee, 1997) that were aligned with Ohio's Academic Content Standards and the NSES (NRC, 1996) in conjunction with current COSI exhibits. Project ASTER III was built upon a cadre of ASTER I and II participants who initially explored inquiry-based teaching through NSF-sponsored kit-based programs (i.e., FOSS, STC). Project ASTER III spanned the course of one year and included the following three phases.

\section{Phase 1: Spring 2004}

In order to improve the inquiry-based teaching skills of the teachers, the first phase of ASTER III engaged 26 teachers in a series of five professional development seminars where COSI team members also served as consultants, thus establishing a foundation for the Summer Institute (SI) by examining key components of inquiry-based science teaching with an emphasis on designing and implementing lessons using the 5E-learning model (Bybee, 1997). During the five seminars, the teachers also explored topics such as scientific inquiry, scientific literacy, and assessment in science as outlined in the NSES (NRC, 1996). Each seminar engaged the teachers as they participated in inquiry-based $5 \mathrm{E}$ learning model lessons that were co-planned and co-facilitated by a university science educator, a university scientist, and COSI museum science educators. Phase 1 also included a planning retreat for SI scientists, educators, and COSI team members in order to become more familiar with the exhibits at COSI.

\section{Phase 2: Summer 2004}

The second phase of ASTER III focused on the integration of COSI exhibits with state and national science education standards and the exploration of inquiry as the teachers were engaged in an intense eight-day SI held at COSI. Here, the teachers participated on grade-level "ASTER Teams" consisting of three teachers, a university scientist, a COSI team member, and a science educator. These teams developed 5E learning model science lessons (Bybee, 1997) that correlate with the state and national science standards and COSI exhibits. In addition to the development of lessons, the teachers were involved in multiple inquiry-based experiences through their own exploration of exhibits. A compendium of lessons has been compiled for dissemination to all of Ohio's teachers and has been posted on the COSI website (www.cositoledo.org). The goal of Phase 2 was to develop lessons that other teachers could implement on future visits to the museum.

The SI was distinctive in nature in that a core team approach incorporating a scientist helped the teachers improve content knowledge, and a science educator ensured that the pedagogy was consistent with state and national standards. Also, the involvement of COSI team members on each team was critical as these individuals will be able to assist future teachers who are not part of ASTER in the facilitation of these lessons to teachers from other schools after the completion of ASTER III. 


\section{Phase 3: Fall 2004}

The focus of Phase 3 was on the dissemination and replication of the efforts of ASTER. The ASTER III teachers brought their students to COSI for a field trip to pilot test their lessons which were developed during the SI. Lesson refinement and modifications were further made based upon these field tests. Furthermore, dissemination occurred through teacher presentations at the local, regional, and state science education conferences.

\section{Research Methodology}

\section{Research Question}

To evaluate the cognitive impact of integrating an informal education center in the professional development model, the following primary research question was examined: How did the ASTER III model of professional development impact teachers' self-efficacy and perceptions about inquiry-based science teaching?

\section{Participants}

The sample for this study included 26 early childhood (grades K-3) inservice teachers from public and private schools in northwest Ohio who participated in previous ASTER I or II professional development projects. These previous ASTER I and II projects resulted in a pronounced desire from the teachers and administrators in the participating schools to expand and continue their participation in an effort to achieve systemic change in their schools. ASTER I and II included a component in the SIs that addressed how to integrate community resources into the classroom. Therefore, ASTER III expanded this critical component and focused on integrating COSI Toledo with the Ohio Academic Content Standards. Because of the background knowledge and experience afforded during ASTER I or II, the teachers were invited to participate as teacher leaders and curriculum developers during ASTER III. ASTER III teachers possessed teaching experience ranging from three to 20 years with a vast difference in their exposure and comfort levels regarding science teaching.

\section{Design and Procedure}

Both quantitative and qualitative methods were used to analyze the data. The quantitative review consisted of two participant surveys that were conducted to collect information about teachers' beliefs about inquiry-based teaching and their beliefs about science teaching in general.

Teachers' beliefs about inquiry-based teaching were measured using a newly developed Survey of Teacher Beliefs in Inquiry-Based Teaching (STBIBT). Teachers' beliefs about science teaching in general were measured using an existing instrument, the Science Teaching Efficacy Belief Instrument (STEBI-A; Riggs \& Enochs, 1990). Both surveys were administered to the participants after the two-week SI (i.e., post-SI) and then at the end of the project (i.e., post-COSI). The baseline data about the teachers' beliefs about inquiry-based teaching were collected before the SI (i.e., pre-SI). The baseline data of teachers' beliefs in science teaching in general were established using teachers' post responses to the STEBI-A survey administered during the ASTER I and II projects. (Note: All of the ASTER III participants participated in either ASTER I or ASTER II.) 
The STBIBT included 28 questions on a 4-point Likert scale ranging from strongly disagree to strongly agree without a neutral point as well as the question asking the teachers to give their self-rating of engagement in inquiry-based teaching from not engaged to somewhat engaged to very engaged. Prior to the analysis, six negatively worded questions on this instrument were reversed (i.e., questions 18, 19, 20, 21,22 , and 27) to ensure that all the items measured teacher beliefs in the same direction and that a higher rating would mean greater agreement. The scale for questions 25 and 26 was kept without change because after learning about how to implement inquiry, teachers should realize that it does require more preparation and set-up time compared to traditional pedagogy. However, the level of time for teacher preparation and set-up would likely be reduced as teachers become more comfortable with inquiry-based teaching. Rasch $(1960,1980)$ reliability (similar in interpretation but a more accurate measure of clarity and consistency within the instrument than the traditional Cronbach alpha) of the new instrument was calculated to be 0.76 . For assessments of this type using relatively small populations, this level suggests that the data originating from this instrument are highly stable and quite useful.

As mentioned, STEBI-A (Riggs \& Enochs, 1990) was used to measure science teaching efficacy. The STEBI-A consists of 25 questions about teacher beliefs about their science teaching on a 5-point Likert scale with a neutral point. Riggs and Enochs revealed, "The STEBI is a valid and reliable tool for studying elementary teachers' beliefs toward science teaching and learning" (p. 633). This instrument measures personal self-efficacy (i.e., the degree to which science teachers believe they can succeed in teaching science) and outcome expectancy (i.e., the degree to which science teachers expect their students to succeed as a result of their teaching). The participants were asked to indicate their level of agreement with each of the survey items. Consistent with the prior uses of this instrument reported in the literature, questions $3,6,8,10,13,17,19,20,21,22,24$, and 25 were reversed.

To assess group change in teacher beliefs about both inquiry-based teaching and science teaching in general, repeated measures ANOVAs were conducted. Additionally, chi-square tests were performed to examine individual change in distribution of teacher self-ratings of their engagement in inquiry-based teaching (STBIBT, question 29) as well as their agreement with each STBIBT item. Percentages of teachers agreeing and disagreeing with each statement at the pretest were treated as the expected value at the posttest if no change occurred. A similar analysis was conducted to identify the areas in which the ASTER project had been the most successful by comparing teacher beliefs (percentages of teachers agreeing and disagreeing with each STEBI-A statement) at the end of ASTER I and II with teacher beliefs at the end of ASTER III (post-COSI).

Finally, participants submitted anonymous written final reflections at the end of the project. Specifically, the participants were asked to describe their professional development experience in Project ASTER III. A qualitative review of 26 participant final reflections was used to cross-reference the results of the surveys. To identify themes, a review of the final reflections was conducted by two independent reviewers, one science education faculty member, and one science education graduate student. Common themes were identified and defined. Themes were coded, and those teacher quotes that best exemplified the final theme were identified. Only themes that showed a high level of inter-rater reliability were included in this report. The three emerging themes from the analysis of the qualitative data are reported in the "Results" section. 


\section{Results}

\section{Teacher Beliefs About Inquiry-Based Teaching}

All the teachers regardless of their participation in the ASTER III professional development program agreed or strongly agreed that inquiry-based teaching requires doing hands-on activities, increases student excitement about learning, helps students become more involved in the learning process, and challenges students to communicate what they already know. Additionally, regardless of the time of the STBIBT administration, almost all the teachers agreed that inquiry-based teaching helps students enjoy science, builds upon students' prior knowledge, promotes cooperative learning, helps retain content knowledge, and develops higher order thinking skills. More than $80 \%$ of the participants agreed that inquiry-based teaching encourages students to read more science literature, requires more materials and resources than usual, requires getting supplies to refill kits, and requires more teacher preparation time. More than $70 \%$ of the teachers agreed that inquiry-based teaching is supported by parents and disagreed that inquiry-based teaching does not work for students who require more structure in their learning. More than $60 \%$ disagreed that it requires small classroom size. In other words, the majority of the teachers started out and continued throughout ASTER III to be optimistic about using inquiry-based teaching with all types of learners in a realistic environment of large classroom sizes. These could be the beliefs that motivate teachers to learn more about inquirybased teaching and guide their decisions to participate in professional development programs such as ASTER. The teachers were split throughout the program in their beliefs that inquiry-based teaching was difficult to assess. This might be the area to focus on in future program design and implementation.

Consistent with the above descriptive results, no statistically significant change in mean ratings was found in teacher beliefs about inquiry-based teaching. The repeated measures ANOVA test was not significant $\left(F_{2,19}=0.625, p=0.546\right)$. One possible explanation of these findings is the ceiling effect because the participants were already in high agreement or expected disagreement with more than half of the statements at the time of the pretest. Possible instrument revision may be recommended for a more valid measurement of change in beliefs.

However, when the percentages of teachers agreeing or disagreeing with the STBIBT items were compared pre-SI, post-SI, and after the COSI field trip using chi-square tests, several findings pointed to the positive effect of the SI, COSI, and the overall ASTER III program. Thus, after the SI, all teachers (i.e., a significant decrease in disagreement by $12 \%$ ) agreed that inquiry-based teaching requires finding out students' knowledge of the subject matter (item $1, \chi^{2}=12.0, p<0.01$ ). This positive change in their beliefs remained stable throughout the COSI field trip experience. Additionally, the COSI experience had a positive significant impact on teacher beliefs that inquiry-based teaching promotes individualized learning, helps students explore topics in depth, requires journal writing by students, and suits all learning styles. Significantly fewer teachers disagreed with each of these statements after their participation in COSI (item 14, $\chi^{2}=9.6, p<0.01$; item 16, $\chi^{2}=8.7, p<0.01$; item $3, \chi^{2}=4.7, p<0.05$, and item 17, $\chi^{2}=8.3, p<0.01$ ), while there was no significant change from pre- to post-SI. A significant decrease was also observed in the number of teachers disagreeing that inquiry-based teaching is more effective when team-teaching is possible (item $20, \chi^{2}=5.3, p<0.05$ ).

The results of the chi-square analysis also identified additional areas of program improvement. Thus, significantly more teachers disagreed after the SI 
and COSI field trip that inquiry-based teaching increases students' apprehension because they are not given ideas and content upfront (item $18, \chi^{2}=18.8, p<0.001$ ). Similarly, a significantly greater number of teachers agreed that inquiry-based teaching requires more time to set up after the SI (item 26, $\chi^{2}=5.0, p<0.05$ ), and this trend was stable through the COSI experience. Finally, a spike was noted in that significantly more teachers believed that inquiry-based teaching was developed sufficiently for lower grades after the SI (item 23, $\chi^{2}=10.9, p<0.01$ ), but the trend reversed after the COSI field trip $\left(\chi^{2}=8.5, p<0.01\right)$.

Implementation-wise, none of the participants reported that they were not engaged in inquiry-based teaching. A chi-square analysis revealed that the change in teacher ratings of engagement was significant from pre- to post-SI $\left(\chi^{2}=4.526\right.$, $p<0.05)$ and stayed significant through post-COSI $\left(\chi^{2}=7.912, p<0.001\right)$. This change was significant for the categories of somewhat engaged and very engaged - that is, significantly fewer teachers rated themselves as somewhat engaged and significantly more teachers rated themselves as very engaged in inquiry-based teaching after the SI. The change from post-SI to post-COSI was not significant $\left(\chi^{2}=0.522, p=0.47\right)$.

\section{Teacher Beliefs in Teaching Science (STEBI-A)}

On the STEBI-A survey regardless of participation in any ASTER professional development program, less than $1 \%$ disagreed (and very few were uncertain) that they are continually finding better ways to teach science, understand science concepts well enough to be effective as teachers, and welcome and are able to answer student questions, and that an effective teaching approach is related to improved academic performance of students. Almost $85 \%$ of the teachers disagreed regardless of the time of the survey that effective science teaching has little influence on academic achievement of students with low motivation, that they are not very effective in monitoring science experiments, and that they are at a loss as to how to help students understand science concepts and how to turn students on to science. Two thirds of the participants agreed that improved student performance in science can be attributed to extra efforts exerted by teachers, that usually low-achieving students improve when given extra attention by a teacher, that teachers are generally responsible for student achievement in science, and that there is a direct relationship between student achievement and interest in science and teacher effectiveness. Similar to the findings from STBIBT, these STEBI-A beliefs contributed to the ceiling effect in that the participants were already in high agreement or expected disagreement with these survey items. Not surprisingly, the results of the dependent $t$-test comparing mean ratings of beliefs after the SI and after the COSI field trip in ASTER III were not significant $\left(t_{20}=-0.764, p>0.05\right)$. Possible instrument revision may be recommended for a more valid measurement of change in these beliefs.

However, when the chi-square tests were performed comparing percentages of teachers agreeing or disagreeing with the STEBI-A items at different points in time and across ASTER programs, some interesting changes were found, pointing to the positive effect of the SI, COSI, and overall ASTER effect. Thus, significantly more ASTER III teachers (from $12 \%$ after the SI compared to $71 \%$ after COSI) disagreed after the COSI field trip that trying very hard does not make them better teachers (item $3, \chi^{2}=882, p<0.001$ ), that they generally teach science ineffectively (item 8 , $\chi^{2}=317, p<0.001$, and that they do not have the necessary skills to be effective science teachers (item 19, $\chi^{2}=769, \mathrm{df}=1, p<0.001$ ). A similar trend was also observed for these beliefs during ASTER I and ASTER II, suggesting that ASTER is effective but is needed on a continuous basis to reinforce these beliefs in the 
teachers. Without professional development, the teachers are likely to revert back to the lack of efficacy in these areas.

Other findings for ASTER III participants include high uncertainly among the teachers (almost 30\%) with regard to blaming low science achievement on teachers, being able to help all students, and thinking that parents attributed increased interest in science to teacher performance. Given that the results for the same beliefs from ASTER I and ASTER II did not show any particular trend and were highly unstable, these seem to be the areas where the effect of ASTER professional development is not as clear.

Finally, three themes emerged from the analysis of the qualitative data from the participant journals: (1) impact on teacher understanding of inquiry, (2) increased confidence about science teaching, and (3) benefits of collaboration. The following quotes exemplify the first theme, impact on teacher understanding of inquiry:

The summer session at COSI was awesome. We had to ask a testable question and explore erosion using sand and water. It really helped me understand how to conduct an inquiry-based lesson. Actually exploring the exhibits ourselves and asking testable questions gave me the understanding I need to plan a lesson using the 5 E Model. (Grade 2 teacher)

I learned so much about how force and incline have an effect on erosion. I remember learning about erosion in school. We were basically made to memorize the effect of erosion, and we had to watch a film about it. I learned so much more by exploring at COSI in one day than I did during that science unit in elementary school. The best part was that I had the chance to find out the answer to some of my questions on my own. It made me feel smart and I know my students feel that same way. They feel better about learning and will never forget what they learned. (Grade 2 teacher)

Although I used experimentation and observation to guide my instruction, I realized through ASTER III that many of my methods were flawed and inquiry wasn't totally integrated as a part of my lesson design and instruction. Although the students explored and collected data, I was primarily the one who studied the data, explained the data, and made the connections for my students through my instruction. The children were merely along for the ride. Now I realize the value of inquiry and how to implement it. (Grade 3 teacher)

The second theme that emerged in the teacher journal responses is entitled increased confidence about science teaching. Sample quotes include the following:

When I brought my class to COSI, I was able to teach my students better than I ever could have without this experience. I feel much more confident in my knowledge as I explain physical science to my students. (Grade 2 teacher)

I have gained confidence and a better understanding of the importance of science teaching. I am happy to say that I am a better science teacher now. (Grade 1 teacher)

This program has given me the opportunity to grow in science as well as science teaching ... being part of this program has given me more understanding and confidence that I can be as successful as I want to be. (Grade 3 teacher) 
ASTER III was an invaluable experience that truly made me reflect on what I teach and the way that I teach. It also helped me to realize the missing component in my science instruction-real inquiry. I now feel that I can implement these strategies into my classroom. (Grade 1 teacher)

All of what I experienced increased my confidence as both a teacher and student of science. (Grade K teacher)

The final theme emerging from the journal responses refers to the importance of collegial collaboration in the development of high-quality inquiry-based lessons as well as the understanding of science content knowledge. This theme is entitled benefits of collaboration. Sample quotes include the following:

One portion of ASTER III that was most beneficial was working with other members of the class that taught at the same grade level. The educator that worked in our groups was helpful and supportive of our ideas and gave suggestions as we went through COSI. The scientist who worked with us was also quite helpful. He explained concepts in a scientific manner that we may have completely misunderstood otherwise. It was nice to have the background knowledge so that we as teachers have a clear understanding. (Grade 2 teacher)

Working closely with our team and focusing on the exhibits broadened my science knowledge. (Grade K teacher)

\section{Discussion}

This research project set out to examine how the ASTER III model of professional development impacted teacher self-efficacy and perceptions about inquiry-based science teaching. A summary of the teachers' beliefs that were stable regardless of the time of the administration of the survey is found in Tables 1 and 2. As noted, the majority of teachers already possessed very positive efficacy beliefs and beliefs about inquiry-based science teaching throughout the course of the project. Therefore, it is not surprising that a more holistic analysis technique (i.e., repeated measures ANOVA or a dependent $t$-test) was unable to detect a significant difference between any administrations of the test. The ASTER III teachers had already participated in either ASTER I or II. Moreover, the participants were motivated teachers who volunteered for participation in this project. As such, it is likely that these two instruments were unable to detect changes in beliefs due to a ceiling effect. An important note gleaned from this initial analysis is that teachers were split on two beliefs: (1) their perception of the role of good science teaching abilities in helping some students learn science and (2) that inquiry-based teaching is difficult to assess. In sum, the majority of teachers generally believed that inquiry-based science teaching was worthwhile in helping to foster student achievement as it included engaging students in hands-on activities, increasing their excitement to learn science, and challenging them to communicate what they are learning. The teachers also believed they possessed the needed knowledge, skills, and abilities to be an effective science teacher, yet they were more uncertain of how their role as an effective science teacher could overcome other obstacles impeding student learning. 
Stable beliefs that inquiry-based teaching ...

$\%$ Disagree \% Agree

Requires doing more hands-on activities.

Increases student excitement about learning.

Helps students become more involved in the learning process.

Encourages students to read more science literature.

Builds upon students' prior knowledge.

$\begin{array}{rr}0 & 100 \\ 0 & 100 \\ 0 & 100 \\ 16 & 84 \\ 2 & 98 \\ 0 & 100 \\ 1 & 99 \\ 4 & 96 \\ 1 & 99 \\ 1 & 99 \\ 74 & 26\end{array}$

Challenges students to communicate what they already know.

Helps students enjoy and look forward to science.

Helps students better retain content knowledge.

Promotes student cooperative learning.

Develops higher order thinking skills.

Does not work for students who require more structure in their learning.

Requires more materials and resources than usual.

Requires small classroom size.

Requires getting supplies to refill kits needed to teach inquiry-

based science.

Requires more teacher preparation time than usual.

Table 2. Summary of Findings for Efficacy Beliefs that Stayed Unchanged During any ASTER Intervention

Stable Efficacy Beliefs about Science Teaching:

I believe that ...

\% Disagree* \% Agree*

Improved student performance in science can be attributed to

extra efforts exerted by teachers.

[l am] continually finding better ways to teach science.

Improved student performance in science can be attributed to

a more effective teaching approach.

I am not very effective in monitoring science experiments.

When a low-achieving student progresses in science, it is usually due to extra attention given by the teacher.

I understand science concepts well enough to be an effective science teacher.

[The] teacher is generally responsible for student achievement in science.

Student achievement in science is directly related to their teacher's effectiveness in science teaching.

If parents comment that their child is showing more interest in science at school, it is usually due to the performance of the teacher.

I am typically able to answer student science questions.

Effectiveness in science teaching has little influence on the achievement of students with low motivation.

When a student has difficulty understanding a science concept, I am usually at a loss as to how to help the student.
13 71

1

3

31

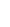


When teaching science, I usually welcome student questions.

96

I don't know what to do to turn students on to science.

students learn science.

*The reported averages were computed and compared for ASTER I posttest, ASTER II posttest, ASTER III post-SI, and ASTER III post-COSI that did not show significant change (i.e., ASTER I posttest = ASTER II posttest = ASTER III post-SI, and ASTER III post-COSI).

Tables 3 and 4 summarize the significant findings for the teacher inquiry and efficacy beliefs that changed during at least one point of the project. These findings represent those obtained from item-level chi-square analyses. Belief changes that were noted between the pre- and post-SI period (see Table 3) demonstrate that teachers were becoming more certain that inquiry-based teaching helps students become more independent learners and requires the teacher to find out what students know about the subject matter. As a result of the SI, the teachers were also more likely to agree that inquiry-based teaching requires more time to set up than usual. Finally, there was a change in their perceived level of engagement in inquirybased teaching as significantly more teachers reported that they were very (versus somewhat) engaged. Since all these significant findings appear both between the pre- and post-SI and pre- and post-COSI (by extension) but are not found between post-SI and post-COSI, these belief changes can be attributed to the Institute effect.

\section{Table 3. Summary of Findings for Inquiry Beliefs that Significantly Changed During ASTER I, II, or III Interventions}

\begin{tabular}{|c|c|c|c|}
\hline & $\begin{array}{l}\% \text { Disagree } \\
\text { at Pretest }\end{array}$ & $\begin{array}{c}\text { \% Disagree } \\
\text { After SI }\end{array}$ & $\begin{array}{l}\text { \% Disagree } \\
\text { After Cosı }\end{array}$ \\
\hline \multicolumn{4}{|l|}{$\begin{array}{l}\text { Significantly fewer teachers disagreed that } \\
\text { inquiry-based teaching ... [SI effect] }\end{array}$} \\
\hline $\begin{array}{l}\text { - Requires finding out students' knowledge } \\
\text { of the subject matter. }\end{array}$ & 12 & 0 & -- \\
\hline - Requires more time to set up than usual. & 24 & 13 & -- \\
\hline \multicolumn{4}{|l|}{$\begin{array}{l}\text { Significantly more teachers disagreed that } \\
\text { inquiry-based teaching ... [SI effect] }\end{array}$} \\
\hline $\begin{array}{l}\text { - Increases students' apprehension } \\
\text { because they are not given ideas and } \\
\text { content upfront. }\end{array}$ & 32 & 57 & -- \\
\hline $\begin{array}{l}\text { - Helps students become more independent } \\
\text { learners. }\end{array}$ & 4 & 9 & -- \\
\hline \multicolumn{4}{|l|}{$\begin{array}{l}\text { Significantly fewer teachers disagreed that } \\
\text { inquiry-based teaching ... [COSI effect] }\end{array}$} \\
\hline - Promotes individualized learning. & -- & 17 & 5 \\
\hline - Suits all learning styles. & -- & 13 & 5 \\
\hline $\begin{array}{l}\text { - Is more effective when team-teaching is } \\
\text { possible. }\end{array}$ & -- & 30 & 19 \\
\hline • Helps students explore topics in depth. & -- & 9 & 0 \\
\hline
\end{tabular}


Significantly fewer teachers disagreed that inquiry-based teaching ... [ASTER effect]

- Requires use of journal writing by

students.

Note: Change in percentages shown is significant. For example, for the statement "Inquiry-based teaching requires finding out students' knowledge of the subject matter," there was a significant change from pretest to post-SI, but the change from post-SI to post-COSI was not significant.

Teachers became more efficacious about teaching science during this time period as well. After each ASTER Summer Institute, the teachers were more likely to agree that they could explain to students why science experiments worked and that they knew the necessary steps to teach science concepts effectively. Teachers also were more open to the idea of inviting a principal to evaluate their science teaching.

Significant changes to teacher inquiry beliefs that were documented between the post-SI and post-COSI phases of the project (see Table 3) show that teachers were less likely to disagree that inquiry-based teaching promotes individualized learning, suits all learning styles, helps students explore topics in depth, and is more effective with team-teaching. Since all these significant findings appear both between the post-SI and post-COSI and the pre-SI and post-COSI (by extension) but are not found between pre-SI and post-SI, these belief changes can be attributed to the COSI effect. Additional significant changes in teacher efficacy beliefs from post-SI to post-COSI (see Table 4) included teachers being more likely to agree that they teach science effectively, have the necessary skills, and are able to help students improve their science background.

When looking for significant changes in teacher inquiry beliefs from pre-SI to post-COSI (see Table 3), only the belief that inquiry-based teaching requires the use of journal writing by students was found to be novel. Two other beliefs were found to significantly change during each phase of the project-(1) inquiry helps students explore topics in depth and (2) inquiry increases students' apprehension. Thus, these belief changes can be attributed to a general ASTER III effect.

The qualitative data show three themes that emerged: (1) impact on teacher understanding of inquiry, (2) increased confidence about science teaching, and (3) benefits of collaboration. Interestingly, all of these themes are supported by the quantitative data. Teacher understanding of inquiry relates well to the significant changes in the following teacher beliefs: I can explain to students why science experiments work, I have the necessary skills to teach science, and an inadequate science background of a student could be overcome by good teaching. Similarly, increased confidence is noted by the significant changes in teacher efficacy, both outcome expectancy and self-efficacy, including the following: I am typically able to answer student science questions, I teach science as well as most subjects, I understand science concepts well enough to be an effective science teacher, and an inadequate science background of a student can be overcome by good teaching. The final theme regarding the benefits of collaboration is supported by the belief change that inquiry-based teaching is more effective with team-teaching. 


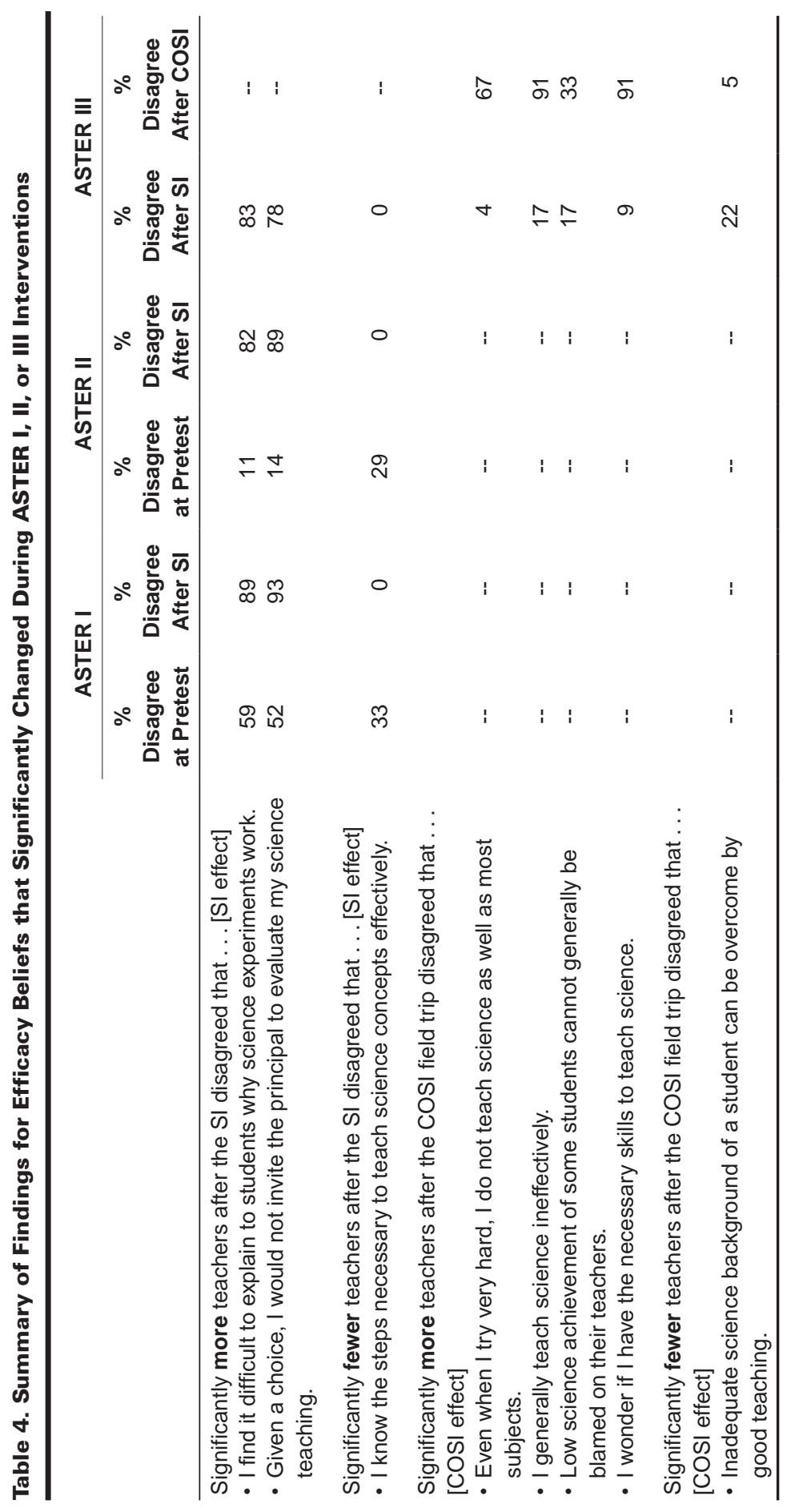


As previously described and in agreement with Ajzen (1985), it is likely that ASTER III teachers are well on their way to more effectively implementing inquiry-based teaching strategies in the classroom. From the onset of the project (and possibly as a result of other professional development experiences), the teachers possessed a positive attitude toward the behavior beliefs about the utility of inquiry-based teaching. These beliefs were further developed in both the SI and as a result of the COSI field trip and related classroom experiences. As a result of the sustained professional development delivered by a team of professional developers representing the sciences, education, and a community partner, the teachers' SN beliefs were enhanced as they believed inquiry-based teaching was more effective with team-teaching, and they were more likely to invite the principal to evaluate their teaching. The qualitative data also suggest that the teachers felt supported as noted by the theme relating to collaboration. Finally, the PBC beliefs of the teachers were also enhanced as several self-efficacy beliefs (both teacher efficacy and outcome expectancy) were fostered as a result of the professional development experience. Qualitative data also supported this notion as noted by the increased confidence and understanding of the inquiry process themes.

Similarly, Bandura (1997) suggested that self-efficacy is an essential determinant of motivation to enact a given behavior. As earlier described, self-efficacy is comprised of both teacher efficacy (i.e., confidence in the knowledge, skills, and abilities needed to enact the behavior) and outcome expectancy (i.e., belief that teacher knowledge, skills, and abilities can indeed overcome obstacles to student learning). Both of these constructs are accounted for in the Ajzen (1985) model, but Bandura specifically discussed the importance of outcome expectancy. Many professional development models are successful at enhancing teacher efficacy, but few are able to enhance outcome expectancy (Enochs, Posnanski, Riggs, \& Shroyer, 1997). The ASTER III project was successful in helping teachers foster positive beliefs regarding their role in overcoming obstacles to learning. Furthermore, Bandura has shown that efficacy beliefs can be fostered by one of four ways: (1) vicarious success, (2) experiencing success, (3) emotional arousal, and (4) persuasion. The ASTER III model provided opportunities for all of these strategies. Teachers were "persuaded" that inquiry-based teaching was at the core of effective science teaching. These teachers heard scientists, university science educators, master teachers, and COSI team members passionately espouse their support for this strategy. The effectiveness of inquiry-based teaching was modeled regularly during the SI so they could experience success vicariously. Moreover, they experienced student success first-hand during the COSI field trip experience and related classroom activities as they had frequent opportunities to assess student learning and motivation during these phases. Finally, emotions were aroused throughout the experience. Again, the ASTER III professional development teams were passionate and enthusiastic about inquiry-based teaching and the teachers' students were highly motivated to go to COSI and learn science via inquiry.

In sum, both quantitative and qualitative analyses support that teacher efficacy beliefs and beliefs about inquiry-based teaching were positively and significantly impacted by ASTER III. Some of the significant changes can be attributed to the SI phase of the model, while other changes were related to the COSI field trip experience and classroom activities. Thus, both aspects of the model seem essential. Follow-up studies to assess whether or not these teacher beliefs are sustained over time would be valuable. Classroom observations of teachers coupled with interviews might further reveal if and how efficacy and inquiry beliefs are enacted in the classroom. 


\section{References}

Ajzen, I. (1985). From intentions to actions: A theory of planned behavior. In J. Kuhl \& J. Beckman (Eds.), Action control: From cognition to behavior (pp. 11-39). New York: Springer-Verlag.

Bandura, A. (1981). Self-referent thought: A developmental analysis of self-efficacy. In J. H. Flavell \& L. Ross (Eds.), Social cognitive development: Frontiers and possible futures (pp. 200-239). New York: Cambridge University Press.

Bandura, A. (1997). Self-efficacy: The exercise of control. New York: Feeman.

Brickhouse, N. (1994). Bringing in the outsides: Reshaping the sciences of the future. Journal of Curriculum Studies, 26(4), 401-416.

Bybee, R. (1997). Achieving scientific literacy: From purposes to practices. Portsmouth, NH: Heinemann.

Czerniak, C. M., \& Chiarelott, L. (1990). Teacher education for effective science instruction-A social cognitive perspective. Journal of Teacher Education, 41(1), 49-58.

Czerniak, C. M., \& Shriver, M. (1994). An examination of pre-service science teachers' beliefs and behaviors as related to self-efficacy. Journal of Science Teacher Education, 5, 77-86.

Duran, E., \& Ballone-Duran, L. (2005). Project ASTER: A model staff development program and its impact on early childhood teachers' self-efficacy. Journal of Elementary Science Education, 17(2), 1-12.

Enochs, L. G., Posnanski, T., Riggs, I. M., \& Shroyer, M. G. (1997, January). A review of science teaching efficacy research. Paper presented at the annual meeting of the Association of Teachers of Science, Cincinnati, $\mathrm{OH}$.

Falk, J., \& Dierking, L. (1997). School field trips: Assessing their long-term impact. Curator, 40, 211-218.

Griffin, J., \& Symington, D. (1997). Moving from task-oriented to learning-oriented strategies on school excursions to museums. Science Education, 81, 793-799.

Kisiel, J. (2006). Making field trips work: Strategies for creating an effective learning experience. The Science Teacher, 72(10), 46-48.

Levitt, K. E. (2001). An analysis of elementary teachers' beliefs regarding the teaching and learning of science. Science Education, 86, 1-22.

Lumpe, A. T., Czerniak, C. M., Haney, J. J., \& Beltyukova, S. (2004). Teacher beliefs: Impact of professional development and influence on student achievement. Paper presented at the annual meeting of the Association of Teachers of Science, Nashville, TN.

Lumpe, A. T., Haney, J. J., \& Czerniak, C. M. (2000). Assessing teachers' beliefs about their science teaching context. Journal of Research in Science Teaching, 37(3), 275-292.

McComas, W. F. (2006). Science teaching beyond the classroom: The role and nature of informal learning environments. The Science Teacher, 72(10), 26-30.

Morrell, P. D. (2003). Cognitive impact of a grade school field trip. Journal of Elementary Science Education, 15(1), 27-34.

Moseley, C., Reinke, K., \& Bookout, V. (2003). The effect of teaching outdoor environmental education on preservice teachers' self-efficacy. Journal of Elementary Science Education, 15(1), 1-13.

National Research Council (NRC). (1996). National science education standards. Washington, DC: National Academy Press. 
National Science Teachers Association (NSTA). (1999). NSTA position statement on informal science education. Retrieved September 29, 2009, from nsta.org/ positionstatement\&psid=13.

Plourde, L. A. (2002). The influence of student teaching on pre-service elementary teachers' science self-efficacy and outcome expectancy beliefs. Journal of Instructional Psychology, 29(4), 245-253.

Price, S., \& Hein, G. E. (1991). More than a field trip: Science programmes for elementary school groups at museums. International Journal of Science Education, 13(5), 505-519.

Ramey-Gassert, L., Shroyer, G. M., \& Staver, J. (1996). A qualitative study of factors influencing science teaching self-efficacy of elementary level teachers. Science Education, 80(3), 283-315.

Ramey-Gassert, L., Walberg III, H. J., \& Walberg, H. J. (1994). Reexamining connections: Museums as science learning environments. Science Education, 78, 345-363.

Rasch, G. (1960). Probabilistic models for some intelligence and attainment tests. Copenhagen: Danmarks Paedagogiske Institute.

Rasch, G. (1980). Probabilistic models for some intelligence and attainment tests (Expanded ed.). Chicago: University of Chicago.

Rennie, L., \& McClafferty, T. (1995). Using visits to interactive science and technology centers, museums, aquaria, and zoos to promote learning in science. Journal of Science Teacher Education, 6(4), 175-185.

Riggs, I. M., \& Enochs, L. G. (1990). Toward the development of an elementary teachers' science teaching efficacy belief instrument. Science Education, 74, 625637.

Correspondence regarding this article should be directed to

Emilio Duran

128 Life Sciences Building

School of Teaching \& Learning

College of Education \& Human Development

Bowling Green State University

Bowling Green, $\mathrm{OH} 43403-0247$

Office: (419) 372-1262

Fax: (419) 372-1263

eduran@bgsu.edu

Manuscript accepted October 22, 2008. 